\title{
OPTIMIZATION OF THE PERFORMANCE OF VAPOUR COMPRESSION CYCLE USING LIQUID SUCTION LINE HEAT EXCHANGER
}

\author{
Abdulkareem Sh. Mahdi Al-Obaidi ${ }^{1, *}$, Ali Naif ${ }^{2}$, Thabit Khalifa Al-Harthi ${ }^{3}$
}

\begin{abstract}
One of the most commonly used refrigeration systems is vapour compression refrigeration system. As saving energy remains a challenge, researchers are putting a lot of efforts into finding efficient solution to improve the performance of vapour compression refrigeration systems. Mechanical subcooling and Liquid Suction Line Heat Exchanger (LSLHX) are approaches that have shown to improve the performance of Vapour Compression Cycle (VCC) systems. This experimental study is conducted to achieve two objectives. First objective is to optimize the heat source and heat sink water volumetric flow rate combination that results in the best performance. In order to evaluate the effect of using subcooling cycle and LSLHX cycle, different flow rate combinations are studied and analysed. Then, to optimize the heat source and heat sink water volumetric flow rate combination that outcome in the optimum performance. Second objective is to optimize the system performance through implementing subcooling and LSLHX. At the optimum water flow rates, the basic VCC performance of the designed system showed better performance compared to the published data. The system performance was improved by $10 \%$ at the optimum flow rate when solely subcooling was used while deteriorated by $47.5 \%$ at full LSLHX.
\end{abstract}

\section{Keywords: Coefficient of Performance, Liquid Suction Line Heat Exchanger, Subcooling, Vapour Compression Cycle}

\section{INTRODUCTION}

Air Conditioning and Refrigeration (ACnR) systems have become an essential need in the recent years due to their importance to carry daily life applications like cooling control and, food and medical preservation. Malaysia, for example, is one of the countries that demand ACnR systems such as air-conditioners and refrigerators in $99 \%$ of its infrastructure; which in return consume $38 \%$ of the overall household energy consumption [1]. Many researches have been conducted to optimize the energy consumption of the ACnR systems by improving the coefficient of performance (COP) of the systems. COP improvement can be achieved either by improving the Cooling Capacity (CC) or by reducing the power consumption or both together.

The performance of ACnR systems improvement can be studied and analysed experimentally, theoretically or numerically. Theoretical and numerical approaches are cost and time saving and can be used to describe the system's ideal behaviour [2]. On the other hand, experimental analysis describes the system's actual operating behaviour. Multistaging, subcooling and vapour injection are the main three methods used to improve the performance of the ACnR systems [3]. However, vapour injection and subcooling are considered the best methods to improve the CC which ultimately improves the COP.

Qureshi and Zubair [4] highlighted that the four main types of subcooling approaches are ambient, external heat sink, mechanical and liquid suction line heat exchanger (LSLHX). In this study, it was reported that implementing mechanical subcooling improved the system performance by $21 \%$. Pottker and Hrnjak [5] studied the effect of subcooling of VCC system utilizing four different refrigerants, namely R410a, R134a, R123yf, and R717. When subcooling has been implemented, the performance has increased by $7 \%, 5.9 \%, 8.4 \%$ and $2.7 \%$ respectively. The highest performance improvement was noted with refrigerants with the higher latent heat of vaporization. LSLHX is a heat exchanger that is used in the ACnR systems to transfer heat from the saturated liquid exiting the condenser to the superheated vapour exiting the evaporator. Besides aiding in increasing the cooling capacity, LSLHX ensures a significant 
advantage to the system as it gets rid of any liquid form refrigerant flowing through the compressor, which correspondingly increases the compressors lifespan.

Aprea et al. [6] and Domanski and Didion [7] studied theoretically the effect of incorporating LSLHX in a basic VCC. The results indicated that the COP of the system increased when refrigerants with high heat capacity, the coefficient of thermal expansion and latent heat of vaporization were used with LSLHX engagement. Also, it was noted that the COP improvement of the LSLHX VCC depends on the type of the refrigerant used. Klien et al. [8] produced a mathematical model to study the effect of the refrigerants on the VCC with LSLHX considering the pressure drop in the suction line of the LSLHX. It was found that the COP increases when using R134a while decreasing when using R22. On the other hand, Navarro-esbrí et al. [9] studied experimentally the effect installing LSLHX on the system's performance using R134a and R1234y. The results showed, when using R1234y the performance dropped by $8.5 \%$ while, when using a VCC LSLHX the performance dropped only by $4.25 \%$. Pottker and Hrnjak [10] executed relatively similar study using R134a and R1234y with and without implementing LSLHX. It was found that the performance increased by $9 \%$ and $18 \%$ respectively when the system was incorporating with an LSLHX. Also, it was noted that the maximum $\mathrm{COP}$ is achieved with $9^{\circ} \mathrm{C}$ of subcooling.

Devecioğlu and Oruç [11] studied the effect of the ambient temperature on a LSLHX VCC system with a variable speed compressor utilizing R453A and R22, and without considering the pressure drop in the suction line of the LSLHX. As the LSLHX is engaged, it was noted that the cooling capacity and power consumption of the system increased as a result of increasing the ambient temperature. Additionally, it was found that the cooling capacity with R22 was higher than R453A. On the other hand, the power consumption for R22 application was higher than R453A in the basic VCC system yet negligible when applying LSLHX. Moreover, the average of the performance of the system improved by $28.5 \%$ and $26 \%$ respectively for R 22 and R $453 \mathrm{~A}$.

One of the most significant drawbacks of adding LSLHX to a VCC is the increment of the power consumption that is supplied to the compressor. This is due to the effect of the pressure drop induced in the suction line of the LSLHX, which ultimately reduces the performance of the overall system. Zhang et al. [12] investigated the possibility of replacing R 134a by R1234yf and R1234ze with incorporating with LSLHX. The maximum pressure-drop for R1234yf and R1234ze was $20 \mathrm{kPa}$ and $14 \mathrm{kPa}$ respectively while $17 \mathrm{kPa}$ for R134a.

Imran et al. [13] studied LSLHX VCC using R245fa that noted the maximum pressure drop was $8 \mathrm{kPa}$. Longo et al. [14] used R410 and R32 to study LSLHX VCC, which noted the maximum pressure drop, was $13 \mathrm{kPa}$. Longo and Gasparella [14], Yan and Lin [15], Jassim et al. [16] and Huang et al. [17] reported the maximum pressure drop when using R134a was $10 \mathrm{kPa}, 27 \mathrm{kPa}, 70 \mathrm{kPa}$ and $9 \mathrm{kPa}$ respectively. The potential factors affecting the performance are the thermodynamic properties of the refrigerant, speed of the compressor, frictional loss, pressure drop and the inclusion of LSLHX.

Taking into account the total pressure drops, frictional losses contributed up to $90 \%$, while the remaining $10 \%$ of pressure losses were due to port, acceleration and gravitational. However, each of the refrigerants used outputs in a different value of pressure drop, which influences the overall performance of the system. Also, the range of the maximum pressure drops using the same refrigerant indicates that the conditions applied to the system do greatly influence the performance of LSLHX and LSLHX incorporated VCCs. In addition, the proportionally linear relationship between pressure drop and kinetic energy per volume was reported.

In order to maximize the COP of the VCC, the relationship between the cooling capacity increment due to the subcooling and the increment of power consumption due to the pressure drop, has to be optimized. Nevertheless, it is discovered that the operating conditions of the refrigeration system are highly significant to achieve the maximum value of COP.

In the industry, VCC systems undergo serval operating conditions. Based on the analysis of previous studies done, the application of LSLHX may be detrimental to the VCC performance under certain system operating conditions or loadings. Hence, there is a need to investigate the behaviour of a VCC cycle that could shift between a basic VCC and LSLHX VCC during on-peak and off-peak loadings respectively.

The focus of this study is, first to design and built an experimental VCC that could analyse both basic and LSLHX VCC system at off-peak and on peak loading respectively. Secondly, to optimize the heat source and heat sink flow rates, and to validate system performance with published data of similar systems. Lastly, to evaluate the effect of LSLHX engaged in subcooling and full LSLHX operation. Also, in previous studies, basic and LSLHX cycles were 
studied by later retrofitting a LSLHX to basic cycle system, which meant that the system had to be evacuated and working fluid had to be recharged during the different stages of the experimentation. Therefore, in order to improve the convenience of experimentation and optimise the overall COP of the system, a VCC system that could shift its operation between a basic and LSLHX needs to be designed, studied and analysed.

\section{METHODOLOGY}

The design of the experimental setup is utilized through manipulating researches conducted by Navarro-Esbri et al. [9] and Devecioğlu and Oruç [11] as depicted in Figure 1. Water is utilized as the heat source and heat sink in this study where it is piped to flow in the opposite direction of the refrigerant flow of the system. The heat exchange generated using this method is higher than the co-counter flow at a given flow rate. The configuration of the system cycle outputs into different types of cycles like basic, LSLHX and sub-cooling cycle.

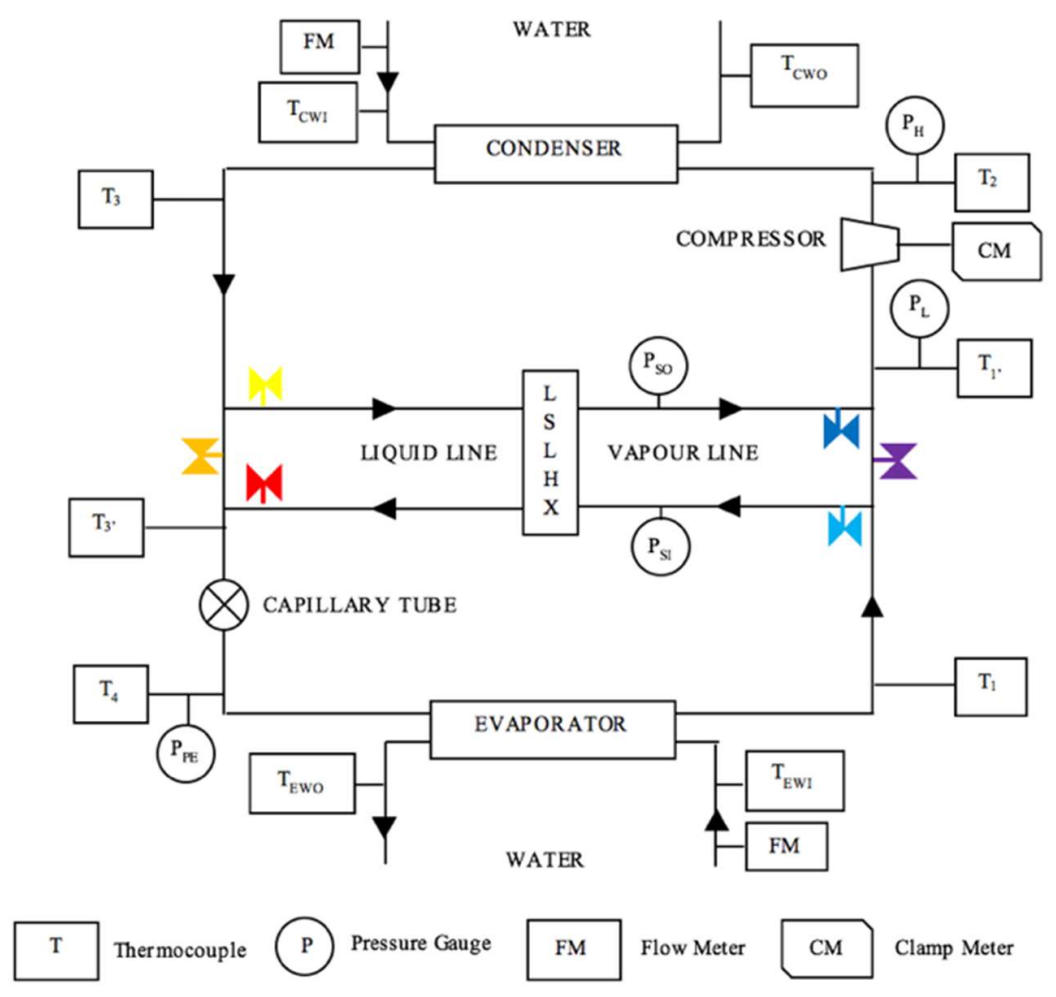

$\begin{array}{llll}T_{1} & \text { Evaporator Outlet Temperature } & T_{E W I} & \text { Evaporator Inlet Water Temperature } \\ T_{1}, & \text { Compressor Suction Temperature } & T_{E W O} & \text { Evaporator Outlet Water Temperature } \\ T_{2} & \text { Compressor Discharge Temperature } & P_{H} & \text { High (Discharge) Pressure } \\ T_{3} & \text { Condenser Outlet Temperature } & P_{L} & \text { Low (Suction) Pressure } \\ T_{3}, & \text { Pre-Expansion Temperature } & P_{P E} & \text { Pre-Expansion Pressure } \\ T_{4} & \text { Evaporator Inlet Temperature } & P_{S I} & \text { Suction Line Inlet Pressure } \\ T_{C W I} & \text { Condenser Inlet Water Temperature } & P_{S O} & \text { Suction Line Outlet Pressure } \\ T_{C W O} & \text { Condenser Outlet Water Temperature } & & \end{array}$

Figure 1. Schematic diagram of the experiential setup

The configuration of the working rig is designed to utilize shut-valves to perform the basic cycle, subcooling cycle, and LSLHX cycle separately as shown in Table 1. The actual working rig used in this study is illustrated in Figure 2. One horsepower is used to compress R22 refrigerant into the refrigeration cycle. 
Journal of Thermal Engineering, Technical Note, Vol. 6, No. 2, Special Issue 11, pp. 201-210, March, 2020

Table 1. Refrigeration cycle configurations

\begin{tabular}{|c|c|c|c|c|c|c|}
\hline \multirow{2}{*}{ Cycle } & \multicolumn{3}{|c|}{ Liquid line } & \multicolumn{3}{c|}{ Suction line } \\
\cline { 2 - 7 } & main & LSLHX in & LSLHX out & main & LSLHX in & LSLHX out \\
\hline basic & ON & & & ON & & \\
\hline LSLHX & & ON & ON & & ON & ON \\
\hline Subcooling & & ON & ON & ON & & \\
\hline
\end{tabular}

Combinations of water flow rates are used to validate the basic vapour compression cycle's performance as seen in Table 2. The flow rate was kept between $1 \mathrm{~L} / \mathrm{min}$ to $1.5 \mathrm{~L} / \mathrm{min}$ due to heating load is higher than cooling load however within this range of flow difference, the system was stable. The best performance achieved out of the nine combinations will be considered as the optimum case. Then, the effect of LSLHX will be studied considering the optimum case flow rates.

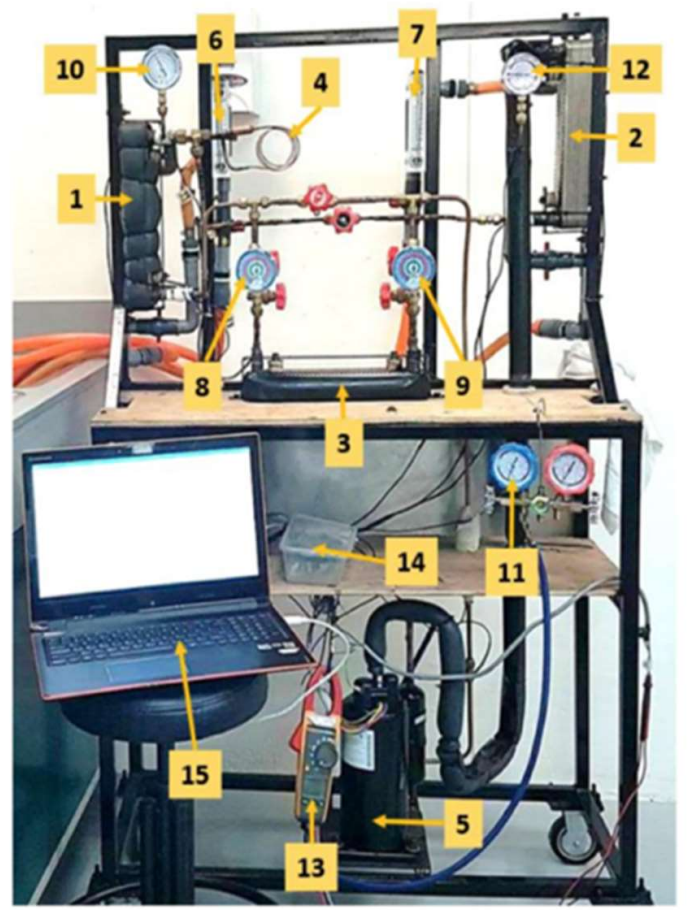
1) Evaporator
2) Condenser
3) LSLHX
4) Capillary tube
5) Compressor
6) Evap. Flowmeter
7) Cond. Flowmeter
8) Pressure gauge (inlet of LSLHX)
9) Pressure gauge (outlet of LSLHX)
10) Pressure gauge (pre-evap)
11) Pressure gauge (suction)
12) Pressure gauge (discharge)
13) Clamp meter
14) Arduino Uno
15) Computer (data logger)

Figure 2. Actual experimental setup

Table 2. Water flowrate combinations cases

\begin{tabular}{|c|c|c|c|}
\hline $\begin{array}{c}\text { Condenser water } \\
\text { flowrate }(1 / \mathrm{min})\end{array}$ & \multicolumn{3}{|c|}{$\begin{array}{c}\text { Evaporator water flowrate } \\
(1 / \mathrm{min})\end{array}$} \\
\hline & 3.5 & 3.75 & 4 \\
\hline 4.5 & 1 (case A) & & \\
\hline 4.75 & $1.25($ case B) & 1 (case D) & \\
\hline 5 & $1.5($ case C) & $1.25($ case E) & 1 (case G) \\
\hline 5.25 & & $1.5($ case F) & $1.25($ case H) \\
\hline 5.5 & & & 1.5 (case I) \\
\hline
\end{tabular}




\section{Evaporator - Cooling capacity}

The cooling capacity of the system is calculated as given in Equation (1).

$$
\dot{Q}_{\text {evap }}=\dot{m}_{\text {Wevap }} C_{p, \text { water }}\left(T_{E W I}-T_{E W O}\right)=\dot{m}_{\text {ref }}\left(h_{1}-h_{4}\right)
$$

where, $\dot{m}_{r e f}$ is the mass flow rate of evaporator heat source water, $C_{p \text {,water }}$ is specific heat capacity of water, $T_{E W I}$ is the evaporator water inlet temperature, $T_{E W O}$ is the evaporator water outlet temperature, $\dot{m}_{r e f}$ is the mass flow rate of the working fluid or refrigerant, $h_{1}$ is the enthalpy of the working fluid at evaporator outlet and $h_{4}$ is the enthalpy of the working fluid at evaporator inlet.

\section{Compressor - Power input}

The power input done by the compressor comp is the product of the potential difference and the current supplied using as in Equation (2).

$$
W_{\text {comp }}=V I=\dot{m}_{r e f}\left(h_{2}-h^{\prime}\right)
$$

where $h_{2}$ is the enthalpy of the working fluid at compressor discharge, $h$ 'is the enthalpy of the working fluid at compressor suction, $V$ is the voltage and $I$ is the current consumed by the compressor.

\section{Coefficient of Performance}

The coefficient of Performance (COP) is the ratio of the cooling capacity and compressor power consumption, as in Equation (3).

$$
C O P=\frac{\dot{Q}_{\text {evap }}}{W_{\text {comp }}}
$$

By substituting Eq. (1) and (2) into Eq. (3), the COP can be also described as in Eq. (4).

$$
C O P=\frac{\dot{m}_{r e f}\left(h_{1}-h_{4}\right)}{V I}
$$

\section{RESULTS AND DISCUSSION}

The system pressure ratio has to be within 3-3.5 to ensure a decent cooling capacity in such refrigeration cycle. The pressure ratios of the water flow rate combinations are depicted in Table 3.

As it can be seen from Table 3, all pressure ratios achieved were within the operation range. In cases, A, D and G pressure ratios are slightly higher than the other cases as these cases have $11 / \mathrm{min}$ flow rate difference. Second highestpressure ratios appeared in cases $\mathrm{H}, \mathrm{E}$ and $\mathrm{B}$ that have $1.25 \mathrm{l} / \mathrm{min}$ flow rate difference. While, the lowest pressure ratio occurred at case $\mathrm{C}$, case I and case $\mathrm{F}$, where the flow rate difference was $1.5 \mathrm{l} / \mathrm{min}$. Thus, the pressure ratio drops when increasing the heat source volumetric flow rate difference between the condenser and evaporator

Table 3. Pressure ratios of the basic cycle combinations

\begin{tabular}{|l|c|c|c|c|c|c|c|c|c|}
\hline Case & A & B & C & D & E & F & G & H & I \\
\hline Pressure ratio & 3.571 & 3.289 & 3.138 & 3.479 & 3.293 & 3.165 & 3.403 & 3.338 & 3.150 \\
\hline
\end{tabular}

The performance of the experimental rig was evaluated against the performance outcomes of one horsepower offthe-shelf air conditioner unit used in the study conducted by Rahman and Rahman [18]. In this study, a comparative study between R22 and R290 was performed to study the performance of (VCC) at three different evaporating temperatures such, $16^{\circ} \mathrm{C}, 19^{\circ} \mathrm{C}$ and $22^{\circ} \mathrm{C}$ the COPs achieved were $3.18,3.19$ and 3.2 respectively. 


\section{Basic VCC cycle}

\section{Power consumption and cooling capacity}

Water is used as the heat source and heat sink in this study as opposed to the study conducted by Rahman and Rahman [18]. Cooling capacity and compressor power consumption of the flow rate combinations are compared with the literature as depicted in Figure 3. The highest cooling capacities were achieved in cases with $11 / \mathrm{min}$ flow rate these cases are $\mathrm{D}, \mathrm{G}$ and A with $2.71 \mathrm{~kW}, 2.704 \mathrm{~kW}$ and $2.68 \mathrm{~kW}$ respectively. Also, the second highest cooling capacities were achieved when the water flow rate difference was $1.25 \mathrm{l} / \mathrm{min}$, which appeared at cases E, H and B at $2.669 \mathrm{~kW}, 2.62 \mathrm{~kW}$ and $2.582 \mathrm{~kW}$ respectively. While the least cooling capacities were achieved, when the flow rate difference was $1.5 \mathrm{l} / \mathrm{min}$ which, appeared in cases F, I and C at $2.548 \mathrm{~kW}, 2.554 \mathrm{~kW}$ and $2.53 \mathrm{~kW}$.

Three flow rate combinations have achieved higher cooling capacity compared to the literature. Namely, these cases are case A, D and G with $1 \%, 3 \%$, and $7 \%$ advantage respectively. As opposed to the cooling capacity results, the lowest average power consumptions achieved in cases with $11 / \mathrm{min}$ flow rate followed with $1.25 \mathrm{l} / \mathrm{min}$ and $1.5 \mathrm{l} / \mathrm{min}$. to explain this behaviour, high flow rate difference causes high compressor power consumption. When the flow rate difference is low, higher power is needed to stabilize the overall system performance. Thus, compressor power consumption was preferable at lower flow rates difference. Nonetheless, the overall power consumption achieved in the 9 flow rate combinations is slightly higher than case X by Rahman and Rahman [18]. However, the cases I, H and G, have made the closest agreement to the literature by $98.64 \%, 98.5 \%$, and $98.3 \%$ respectively. However, the minor difference between the designed working rig and literature may have occurred due to the uncertainties and higher irreversibility in the designed system. These uncertainties are shown in Appendix A, Table A-1. The power consumption varied insignificantly because the minimum power required to operate the compressor was the same, while the minor fluctuations in power consumption were the direct effect of applied cooling load in all cases.

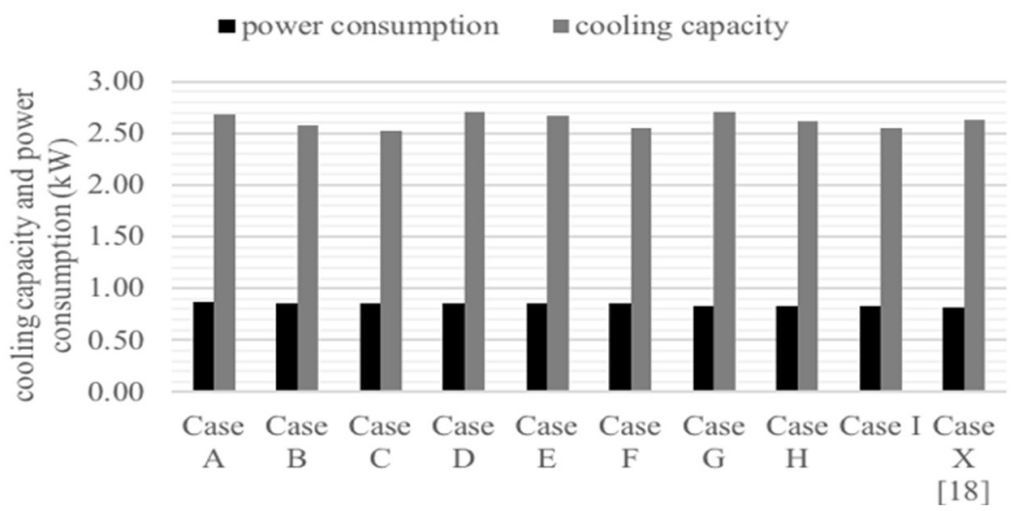

Figure 3. Basic VCC cooling capacity and compressor power consumption comparison between water flow rate combination cases and Case X [18]

\section{Coefficient of Performance (COP)}

$\mathrm{COP}$ is the ratio of cooling capacity over compressor power consumption. COP value can judge the performance of the cooling system wherever the higher COP value the better the cooling performance. The finest COP values can be achieved when cooling capacity is high while the compressor power consumption is low. The comparison between the performance of the 9 flow rate combination cases and the literature is illustrated in Figure 4.

The highest COPs were achieved by cases with $11 /$ min flow rate difference, as the best combination case was G followed by case D with 3.23 and 3.159 respectively. On the other hand, lowest COPs achieved at cases C, F and I when the flow difference was $1.5 \mathrm{l} / \mathrm{min}$. Nevertheless, the case $\mathrm{G}$ achieved $3.85 \%$ better COP value than Case $\mathrm{X}$ by Rahman and Rahman [18]. As the power consumption increase as a result of increased cooling load, the system tends to maintain its performance consistently about its rated performance. 


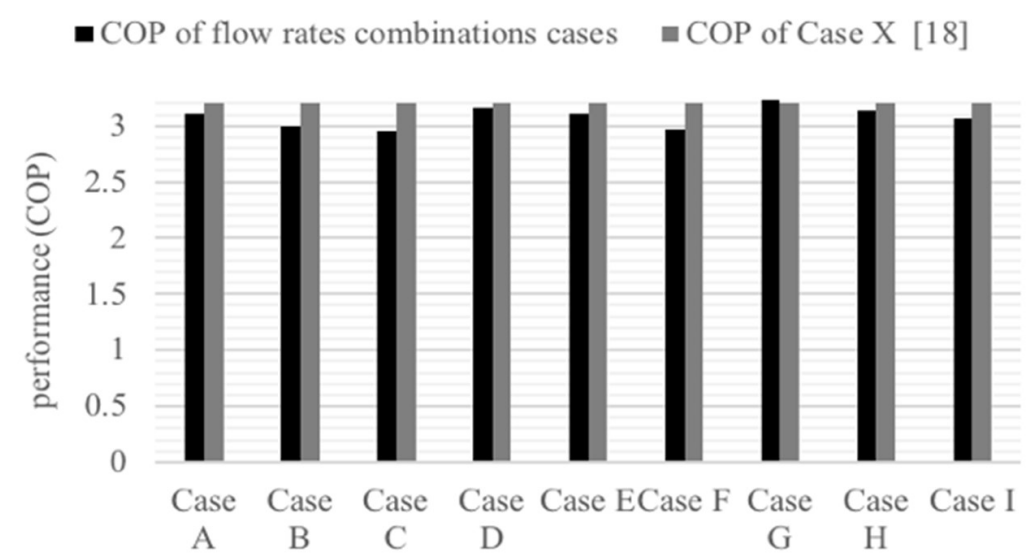

Figure 4. Comparison between the performance of the flow rate combinations cases and Case X [18].

\section{Liquid suction line heat exchanger (LSLHX)}

Based on the results conducted in this study, case $\mathrm{G}$ is chosen to be the optimum case as it has achieved the highest COP value. Case G flow rates were set at $41 / \mathrm{min}$ at the condenser and $51 / \mathrm{min}$ at the evaporator. These operating conditions are taken into account to study the effect of running full LSLHX and subcooling cycles. To study subcooling cycle, refrigerant was permitted to flow as a liquid form in the liquid side of the LSLHX while the suction vapour was permitted to flow in the basic main line. To study the effect of running full LSLHX, both suction and liquid sides of the basic cycle were closed while the suction and vapour lines of the LSLHX were open.

\section{a) Power consumption and cooling capacity}

Comparison between the effect of subcooling cycle and engaging full LSLHX cycle on the cooling capacity and power consumption of the system is illustrated in Figure 5. Cooling capacity has improved by $7.14 \%$ when subcooling system was implemented while it has dropped by $51.28 \%$ when full LSLHX cycle was implemented.

The reduction of the cooling capacity of full LSLHX system can be explained by two observations. Dysfunction of expansion, where it was noted that the working fluid enters and leaves the expansion device (capillary tube) at the similar temperature. LSLHX system was oversized to fit one-horsepower system with R22. In other words, the system was not expanding, because it was overly subcooling and the capillary tubes could not endure the capacity of the liquid. However, the compressor power consumption was reduced when implementing subcooling and full LSLHX by 3\% and $7.93 \%$ respectively. LSLHX compressor power reduction was more significant than subcooling due to the significantly low in the pressure ratio caused by the dysfunction of the capillary tubes.

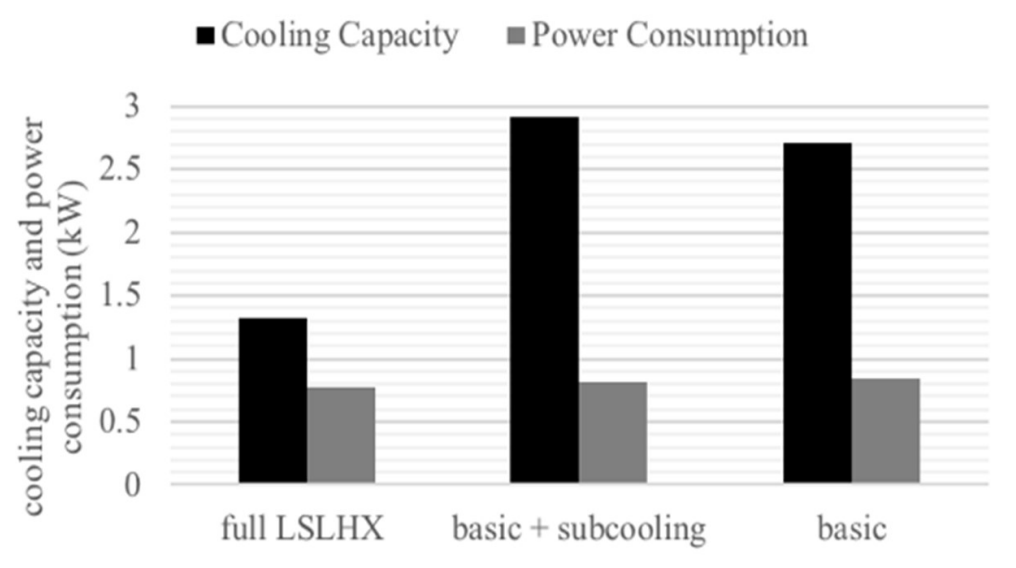

Figure 5. The effect of subcooling and full LSLHX on the performance based on the optimum case. 


\section{b) Coefficient of performance (COP)}

The effect of subcooling and engaging full LSLHX on the COP is illustrated in Figure 6. Based on the results conducted, when implementing subcooling COP increased by approximately $10 \%$ while it dropped by $47.5 \%$ when engaging the full LSLHX. However, the significant drop in the performance of the full LSLHX cycle is due to the low cooling capacity.

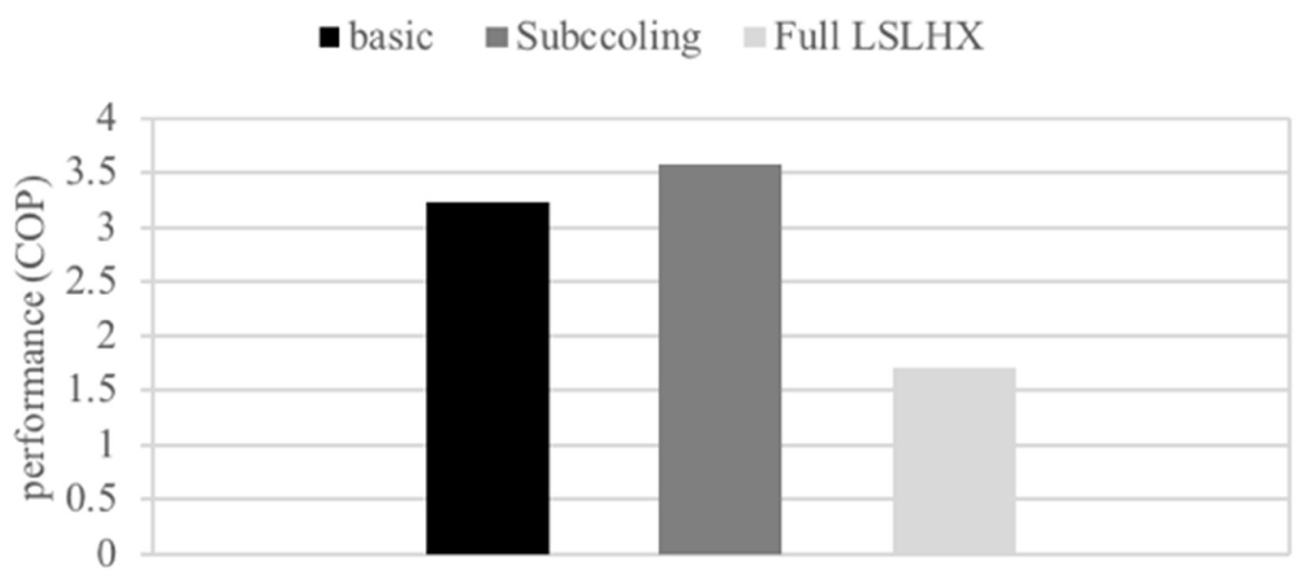

Figure 6. The effect of subcooling and full LSLHX on the performance based on the optimum case

To understand the behaviour of the system under $1 \mathrm{l} / \mathrm{min}$ flow rate, case $\mathrm{A}$, and case $\mathrm{D}$ have been tested using a similar approach as case G. When subcooling was applied, both cases A and D have experienced improvement by $8 \%$ and $3.5 \%$ respectively. The system performance in case A and case D have dropped by $50.6 \%$ and $47.4 \%$ respectively when the full LSLHX has been engaged. Thus, the trend achieved is similar to the optimum case.

Subcooling cycle has significantly improved the performance of the cooling system while full LSLHX cycle was an unstable approach to improve the performance of the system. Qureshi and Zubair [4] and Pottker and Hrnjak [5, 10] have achieved performance improvement when using mechanical subcooling approach as it has increased the cooling capacity and saves energy. On the other hand, the drop in the coefficient of performance at LSLHX cycle can by justified by Domanski and Didion [7] as LSLHX can affect the performance of the cooling system negatively. As the performance of the LSLHX depends highly on the operating condition of the system. In this study, it was found out that to achieve positive results utilizing LSLHX using R22 and R 134a, the difference between condenser and evaporator temperatures must be at least $45{ }^{\circ} \mathrm{C}$ and $13{ }^{\circ} \mathrm{C}$ respectively. However, the temperature difference achieved in the working rig at the optimum case was $22^{\circ} \mathrm{C}$.

There are several approaches that can be considered to overcome the drawbacks occurred when LSLHX was fully engaged in this system. Firstly, to change the working fluid from R22 to R134a. Considering, R134a operates more significantly at low rangers of temperature can operate better under the low range of temperature difference between the evaporator and condenser. Secondly, to change the expansion device from capillary tube to eternally equalizing thermal expansion valve (EETXV) as it provides the cooling systems with significantly more stable expansion process. Moreover, to replace the constant speed compressor used by variable speed compressor (VCC) as it adopts the changes in capacity stabilizes the pressure ratio and the overall performance of the system.

\section{CONCLUSION AND FUTURE WORKS}

In conclusion, the main objective of this study is to optimise the coefficient performance of VCC through implementing liquid suction line heat exchanger (LSLHX). In order to optimise the performance of the basic VCC, cooling capacity and power consumption of all water flowrate combinations were studied. Then, to compare the combination COPs of the water flow rate combinations to literature. However, it was found that the highest COPs and the highest pressure ratios were achieved at combinations with $1 \mathrm{~L} / \mathrm{min}$ water flow rate difference flowed by $1.25 \mathrm{~L} / \mathrm{min}$ and $1.5 \mathrm{~L} / \mathrm{min}$. Furthermore, case $\mathrm{G}$ is considered as the optimum case in this study as it has achieved the highest COP 
value with $3.85 \%$ performance advancement compared to the literature [18]. The optimum case was used to optimise the performance of the solely subcooling cycle, and full LSLHX cycle. Subcooling solely has improved the performance of the system by $9.94 \%$. While, full LSLHX cycle has achieved negative results by $47.42 \%$. The significant decline in performance of the LSLHX cycle can be caused because the LSLHX was oversized which resulted in subcooling beyond the capacity of the expansion device. In order to improve the LSLHX performance in the future works, an alternative expansion device to be used such EETXV to stabilize the expansion process and to adopt changes in capacity. Also, to use alternative working fluid such R134a in the system to achieve the range of the required operating conditions. And, to implement VSC to adopt changes in capacity and to stabilize the pressure ratio and the overall performance.

\section{NOMENCLATURE}

$\begin{array}{ll}C_{p, w a t e r} & \text { Water heat capacity } \\ E E T X V & \text { Eternally Equalizing Thermal Expansion Valve } \\ h & \text { Enthalpy } \\ L S L H X & \text { Liquid Suction Line heat exchanger } \\ \dot{m}_{\text {ref }} & \text { Refrigerant mass flowrate } \\ \dot{m}_{W e v a p} & \text { Evaporator water mass flowrate } \\ P_{H} & \text { High (Discharge) Pressure } \\ P_{L} & \text { Low (Suction) Pressure } \\ P_{P E} & \text { Pre-Expansion Pressure } \\ P_{S I} & \text { Suction Line Inlet Pressure } \\ P_{S O} & \text { Suction Line Outlet Pressure } \\ \dot{Q}_{\text {evap }} & \text { Cooling capacity } \\ T_{1} & \text { Evaporator Outlet Temperature } \\ T_{1}, & \text { Compressor Suction Temperature } \\ T_{2} & \text { Compressor Discharge Temperature } \\ T_{3} & \text { Condenser Outlet Temperature } \\ T_{3}, & \text { Pre-Expansion Temperature } \\ T_{4} & \text { Evaporator Inlet Temperature } \\ T_{C W I} & \text { Condenser Inlet Water Temperature } \\ T_{C W O} & \text { Condenser Outlet Water Temperature } \\ T_{E W I} & \text { Evaporator Inlet Water Temperature } \\ T_{E W O} & \text { Temperature of the outlet of evaporator } \\ V C C & \text { Vapour Compression Cycle } \\ V S C & \text { Variable Speed Compressor } \\ W_{\text {comp }} & \text { Work done by compressor } \\ & \end{array}$

\section{REFERENCES}

[1] Kubota T, Jeong S, Toe DHC, Ossen DR. Energy consumption and air-conditioning usage in residential buildings of Malaysia. J Int Dev Coop, 2011;17(3):61-9.

[2] Naif A, Al-Obaidi ASM, Nassir MH. Effect of evaporator heater power input and refrigerant flow rate on the performance of a refrigerator - Developing empirical models. J Mech Eng Autom, 2015; 5(1):20-8. https://doi.org/10.5923/j.jmea.20150501.03.

[3] Park C, Lee H, Hwang Y, Radermacher R. Recent advances in vapor compression cycle technologies. Int J Refrig, 2015;60:118-34. https://doi.org/10.1016/j.ijrefrig.2015.08.005.

[4] Qureshi BA, Zubair SM. Mechanical sub-cooling vapor compression systems: Current status and future directions. Int J Refrig, 2013; 36(8):2097-2110. https://doi.org/10.1016/j.ijrefrig.2013.07.026.

[5] Pottker G, Hrnjak P. Effect of the condenser subcooling on the performance of vapor compression systems. Int J Refrig, 2015;50:156-64. https://doi.org/10.1016/j.ijrefrig.2014.11.003.

[6] Aprea C, Ascani M, de Rossi F. A criterion for predicting the possible advantage of adopting a suction / liquid heat exchanger in refrigerating system. Appl Therm Eng, 1999;19(4):329-36. https://doi.org/10.1016/S13594311(98)00070-2. 
[7] Domanski PA, Didion D.A, Doyle JP. Evaluation of suction-line/liquid -line heat exchange in the refrigeration cycle. Int J Refrig, 1994;17(7):487-93.

[8] Klein SA, Reindl DT, Brownell K. Refrigeration system performance using liquid-suction heat exchangers. Int J Refrig, 2000;23(8):588-96. https://doi.org/10.1016/S0140-7007(00)00008-6.

[9] Navarro-esbrí J, Molés F, Barragán-cervera Á. Experimental analysis of the internal heat exchanger influence on a vapour compression system performance working with R1234yf as a drop-in replacement for R134a. Appl Therm Eng, 2013;59(1-2):153-61. https://doi.org/10.1016/j.applthermaleng.2013.05.028.

[10] Pottker G, Hrnjak P. Experimental investigation of the effect of condenser subcooling in R134a and R1234yf air-conditioning systems with and without internal heat exchanger. Int $\mathrm{J}$ Refrig, 2015;50:104-13. https://doi.org/10.1016/j.ijrefrig.2014.10.023.

[11] Devecioğlu AG, Oruç V. The influence of plate-type heat exchanger on energy efficiency and environmental effects of the air-conditioners using R453A as a substitute for R22. Appl Therm Eng, 2017;112: 1364-72. https://doi.org/10.1016/j.applthermaleng.2016.10.180.

[12] Zhang J, Desideri A, Kærn MR, Ommen TS, Wronski J, Haglind F. Flow boiling heat transfer and pressure drop characteristics of R134a, R1234yf and R1234ze in a plate heat exchanger with conditions prevailing in the evaporator of organic Rankine cycle units. Int J Heat Mass Transf, 2017;108(Part B): 1787-801. https://doi.org/10.1016/j.ijheatmasstransfer.2017.01.026.

[13] Imran M, Usman M, Yang Y, Park B-S. Flow boiling of R245fa in the brazed plate heat exchanger: Thermal and hydraulic performance assessment. Int J Heat Mass Transf, 2017;110:657-70. https://doi.org/10.1016/j.ijheatmasstransfer.2017.03.070.

[14] Longo GA, Gasparella A. Refrigerant R134a vaporisation heat transfer and pressure drop inside a small brazed plate heat exchanger. Int J Refrig, 2007;30(5):821-30. https://doi.org/10.1016/j.ijrefrig.2006.11.011.

[15] Yan Y-Y, Lin T-F. Evaporation heat transfer and pressure drop of refrigerant R-134a in a plate heat exchanger. J Heat Transf, 1999;121(1):118-27. https://doi.org/10.1115/1.2825924.

[16] Jassim EW, Newell TA, Chato JC. Refrigerant pressure drop in chevron and bumpy style flat plate heat exchangers. Exp Therm Fluid Sci, 2006;30(3):213-22. https://doi.org/10.1016/j.expthermflusci.2005.05.008.

[17] Huang J, Sheer TJ, Bailey-Mcewan M. Heat transfer and pressure drop in plate heat exchanger refrigerant evaporators. Int J Refrig, 2012;35(2):325-35. https://doi.org/10.1016/j.ijrefrig.2011.11.002.

[18] Rahman MM, Rahman HY. Hydrocarbon as refrigerant for domestic air conditioner : a comparative study between R22 and R290. Therm Eng, 2012;53:11976-79.

\section{APPENDIX A}

The uncertainty of the measuring equipments' is in Table A-1.

Table A-1. Uncertainty analysis

\begin{tabular}{|l|l|l|l|}
\hline Apparatus & Parameter & Uncertainty & Unit \\
\hline LM35 & Temperature & \pm 0.75 & ${ }^{\circ} \mathrm{C}$ \\
\hline Pressure gage & Pressure & \pm 2 & $\mathrm{kPa}$ \\
\hline Flowmeter & Volume Rate & \pm 0.2 & $1 / \mathrm{s}$ \\
\hline \multirow{2}{*}{ Clamp meter } & Current & \pm 0.1 & $\mathrm{~A}$ \\
\cline { 2 - 4 } & Voltage & \pm 0.1 & $\mathrm{~V}$ \\
\hline
\end{tabular}

